\title{
Psychiatric morbidity: a multilevel approach to regional variations in the UK
}

\author{
Craig Duncan, Kelvyn Jones, Graham Moon
}

\begin{abstract}
Study objective - To establish whether regional variations in psychiatric morbidity in Britain constitute a distinctive geography of mental health arising from factors that are context-specific at area level or whether these variations are an artifact generated by sampling fluctuations and differing population compositions in areas.

Design - Multilevel modelling techniques were applied to data from the 1984-85 health and lifestyle survey. The outcome was the prevalence of psychiatric morbidity as recorded by the application of the general health questionnaire in this survey.
\end{abstract}

Setting - The analysis was undertaken simultaneously at the individual level, electoral ward level, and regional level for England, Wales, and Scotland.

Participants - A total of 6572 adults were selected from the electoral register.

Main results - Regional variations were detected in crude aggregate general health questionnaire scores but these were found to be the result of sampling fluctuations and varying regional population compositions rather than higher level contextual effects. There was certainly no evidence of a clear north-south distinction in psychiatric morbidity as was suggested by earlier work. In addition, the local neighbourhood did not seem to have any importance beyond the type of people who lived there. A number of individual characteristics was shown to be associated with mental wellbeing but a large degree of individual variation remained unexplained.

Conclusions - In terms of low level psychiatric disturbance it seems that the characteristics of individuals have greater importance than the characteristics of areas, although the latter may still operate as important mediating factors. Multilevel modelling represents a robust statistical method of examining area variations in health outcomes and further work needs to be conducted, particularly on more serious psychiatric conditions.

( $\mathcal{F}$ Epidemiol Community Health 1995;49:290-295)

University of

Portsmouth,

Portsmouth

G Moon

Correspondence to: Mr C Duncan.

Accepted for publication December 1994 area of residence and health has a long tradition in Britain much of the work that has been conducted has been problematic in both conceptual and technical terms. As is now recognised, many studies ${ }^{1-3}$ used area level data only, because information about individuals was not available. ${ }^{4}$ Furthermore, since such studies were primarily concerned with evaluating the association between material deprivation and health, any significant area variations found were often "explained" in terms of the social class composition of the areas $^{5}$ - a tendency likely to have been encouraged by considerable fear among epidemiologists of committing the ecological fallacy. ${ }^{6}$ Some recent area studies, however, have become more sophisticated and suggest that there may be area effects independent of population composition. ${ }^{7-9}$ These show that interest has moved on to assessing the relative importance of the characteristics of areas compared to the characteristics of the people found within those areas, and they suggest that there is an area, or contextual, effect over and above an effect that arises from compositional factors. Consequently, it seems that not only do areas differ but that area itself makes a difference. Health outcomes depend on both individual and area characteristics.

Most of the work on the effects of area on health outcomes has been conducted in relation to physical health. When mental health has been considered, attention has focussed almost exclusively at the subregional level ${ }^{10}$ : most work examines intra-urban variations ${ }^{11}$ and the differences between urban and rural areas. ${ }^{12}$ As psychiatric morbidity is widespread within the population at large - a recent Department of Health report ${ }^{13}$ has suggested that it is as common as heart disease and three times as common as lung cancer - the tendency for mental health research to have ignored larger spatial scales, in particular a regional dimension, is both surprising and disconcerting. Regional location could be expected to provide one important context, shaping and structuring some of the opportunities and constraints of daily living which have importance for individual psychological wellbeing.

Two substantive recent studies have, however, considered the regional dimension to mental health. Both have used data from the 1984-85 health and lifestyle survey. ${ }^{14}$ Blaxter has considered regional variations in "psychosocial health" using a composite index formed from the responses to two questions in the health and lifestyle survey. ${ }^{7}$ Controlling for age, sex, and social class this work showed higher levels of psychiatric morbidity in the north of the country, except in women of non-manual class where the west and the Midlands were 
highest. Blaxter also considered variations at smaller geographical scales and suggested that the local neighbourhood is more significant than the larger region in determining psychosocial health. Another recent study by Lewis and Booth, ${ }^{15}$ also based on information from the health and lifestyle survey, used the responses given when the general health questionnaire $(\mathrm{GHQ})^{16}$ was administered as part of the survey. Again, a greater concentration of psychiatric morbidity was identified in the north of the country than the south but it was suggested that this was probably because of composition rather than area factors. The study concluded tentatively that the nature of the regional variations differed according to the social class position and the immediate, external living environment of individuals. In particular, the north-south difference did not seem to exist for those in social classes I and II and was less marked for those living within urban areas without access to open spaces.

While they provide a useful and conceptually sophisticated introduction to a neglected area of research both of the above studies have technical problems. In Blaxter's work, standardised ratios were used, and to avoid small number problems coarse aggregate groupings were applied. Social class was reduced to two classes and the regional geography of Great Britain was collapsed into just three areas. No other compositional variables were included other than age and gender. A more sophisticated logistic modelling strategy was used in Lewis and Booth's analysis but again a very coarse regionalisation was adopted (the country was divided into five regions) and, most importantly, a traditional, single level, aggregate modelling approach was applied. Such an approach is inherently problematic for the purposes of this present paper given that its central concern is with assessing the relative importance of effects at different levels: the individual, and simultaneously, the area level. As is becoming increasingly recognised, ${ }^{17}$ the study of the size and nature of area variations in health outcomes

Table 1 Data structure applied in the analysis

\begin{tabular}{|c|c|c|}
\hline $\begin{array}{l}\text { No } \\
6572 \\
396 \\
22\end{array}$ & & $\begin{array}{l}\text { Meaning } \\
\text { Individuals } \\
\text { Electoral wards } \\
\text { Regions }\end{array}$ \\
\hline Region & $\begin{array}{l}\text { Electoral } \\
\text { wards }\end{array}$ & Individuals \\
\hline Strathclyde & 18 & 283 \\
\hline \multirow{2}{*}{$\begin{array}{l}\text { East Central Scotland } \\
\text { Rural Scotland }\end{array}$} & 9 & 149 \\
\hline & 11 & 217 \\
\hline \multirow{2}{*}{$\begin{array}{l}\text { Rural North } \\
\text { Industrial North East }\end{array}$} & 15 & 258 \\
\hline & 20 & 371 \\
\hline Merseyside & 7 & 116 \\
\hline \multirow{2}{*}{$\begin{array}{l}\text { Greater Manchester } \\
\text { Rest of the North West }\end{array}$} & 20 & 328 \\
\hline & 18 & 284 \\
\hline West Yorkshire & 12 & 200 \\
\hline $\begin{array}{l}\text { South Yorkshire } \\
\text { Rural Wales }\end{array}$ & 14 & 224 \\
\hline Rural Wales & 10 & 164 \\
\hline Industrial South Wales & 10 & 185 \\
\hline West Midlands Conurbation & 17 & 257 \\
\hline $\begin{array}{l}\text { Rest of West Midlands } \\
\text { East Midlands }\end{array}$ & 19 & 314 \\
\hline East Midlands & 28 & 519 \\
\hline East Anglia & 14 & 270 \\
\hline Devon \& Cornwall & 6 & 115 \\
\hline Wessex & 26 & 415 \\
\hline \multirow{2}{*}{$\begin{array}{l}\text { Inner London } \\
\text { Outer London }\end{array}$} & 16 & 185 \\
\hline & 32 & 454 \\
\hline \multirow{2}{*}{$\begin{array}{l}\text { Outer Metropolitan area } \\
\text { Outer South East }\end{array}$} & 43 & 738 \\
\hline & 31 & 526 \\
\hline
\end{tabular}

is better approached using newly developed multilevel modelling techniques that are capable of working at more than one level simultaneously. ${ }^{18}$ While such techniques have been applied in the study of area variations in physical health and health-related behaviours, ${ }^{19-21}$ they have not been used in studies of mental health outcomes. The present study, therefore, applies a multilevel modelling approach to the GHQ data from the health and lifestyle survey to provide a more sensitive analysis of area variations in mental health in Britain. While the main focus is on regional variations, consideration is also given to the importance of the local neighbourhood.

\section{Methods}

The 1984-85 health and lifestyle survey was based on a multistage sampling design in which individuals, within electoral wards, within electoral constituencies, and within regions were randomly selected. In a multilevel analysis this hierarchical data structure can be explicitly recognised and maintained. Thus, it is possible to consider individuals, who can be described in terms of a wide range of personal socioeconomic characteristics, within a highly refined quantitative representation of the contextual settings in which they reside. As the analysis works at both individual and area levels simultaneously, the ecological fallacy is avoided and more accurate distinctions can be made between variations caused by contextual effects and those that are an artefact generated from variations in the characteristics of people contained within specific areas. In addition, working at more than one level enables relationships to vary according to context. Recognising the multi-layered nature of social life also brings a number of technical advantages. Thus, multilevel models are not affected by the serious mis-estimation problems associated with autocorrelation in traditional, single level regression $^{22-24}$ and ameliorate problems arising from small numbers and sampling fluctuations. ${ }^{25}$

The fundamentals of multilevel modelling as it applies to health research have been covered comprehensively elsewhere. ${ }^{2627}$ The present study focusses on a three level analysis of the health and lifestyle survey data with individuals at level 1 nested within electoral wards at level 2 , nested in regions at level 3 . Unlike previous studies, therefore, which considered one geographical scale at a time, this analysis explores the geography of mental health at two different area levels simultaneously, one local and one regional, thus helping ensure that any area effects are apportioned to the appropriate level. The present study is also able to use a more sophisticated regional classification than that employed by Blaxter and Lewis and Booth The Economist classification which defines 22 regions and essentially represents a subdivision of the standard regions into metropolitan and non-metropolitan areas. The actual data structure used is shown in table 1 .

The analysis models each individual's overall GHQ score (0-30) as a continuous variable. 
This approach is adopted in an initial report detailing the survey's findings ${ }^{14}$ and is justified by research which has shown that if the GHQ is simply dichotomised on the basis of those scoring 5 or more, many of those exceeding this threshold turn out to be "non-cases". ${ }^{28}$ Three types of multilevel model are applied and all were calibrated using the software package $M L 3 .^{29}$ The first represents a simple, "null", three level, random-intercepts model in which the variation in the response variable is "explained" by a single fixed intercept term, the national average GHQ score, and three random terms which apportion the degree of remaining variation in the intercept to each level of the model.

A second model is formed by including a number of fixed explanatory variables which reflect a range of individual level characteristics. In this paper nine, level one explanatory variables were used: age, sex, social class (defined according to the Registrar General's 1980 classification), marital status, employment status, limiting long term illness, immediate external living environment, housing tenure, and ethnicity. This list corresponds to and extends that used by Lewis and Booth. Apart from age, these variables were specified as a set of 17 dummy, indicator variables, coded so that the intercept term in the model would represent the stereotypical respondent to the GHQ in the health and lifestyle survey: an employed woman in social group III-manual who is married, living in an owned house in an urban area with adjacent open space or garden, has no limiting long term illness, and is not from an ethnic minority group. Age was treated as a continuous variable and was centred around the sample mean value of 45 years, and so the stereotypical respondent is also of average age. In this model, the two higher level random terms now assess the ward and regional differences after "controlling" for variations in the composition of areas on the basis of the selected individual characteristics. If these terms are not significant, then area variations are simply an

Table 2 Aggregate average general health questionnaire (GHQ) scores based on the 1984-85 health and lifestyle survey

\begin{tabular}{ll}
\hline Region & $\begin{array}{l}\text { Average GHQ score } \\
(\text { rank })^{*}\end{array}$ \\
\hline Strathclyde & $4 \cdot 36(18)$ \\
East Central Scotland & $3 \cdot 55(5)$ \\
Rural Scotland & $3 \cdot 46(4)$ \\
Rural North & $4 \cdot 04(12)$ \\
Industrial North East & $4 \cdot 51(19)$ \\
Merseyside & $5 \cdot 25(22)$ \\
Greater Manchester & $4 \cdot 95(21)$ \\
Rest of the North West & $3 \cdot 91(10)$ \\
West Yorkshire & $3 \cdot 76(7)$ \\
South Yorkshire & $4 \cdot 33(16)$ \\
Rural Wales & $3 \cdot 15(1)$ \\
Industrial South Wales & $3 \cdot 92(11)$ \\
West Midlands Conurbation & $4 \cdot 34(17)$ \\
Rest of West Midlands & $4 \cdot 30(15)$ \\
East Midlands & $3 \cdot 43(3)$ \\
East Anglia & $3 \cdot 80(9)$ \\
Devon \& Cornwall & $3 \cdot 42(2)$ \\
Wessex & $4 \cdot 08(13)$ \\
Inner London & $4 \cdot 12(14)$ \\
Outer London & $4 \cdot 74(20)$ \\
Outer Metropolitan area & $3 \cdot 66(6)$ \\
Outer South East & $3 \cdot 79(8)$ \\
Total sample & $4 \cdot 03$ \\
\hline
\end{tabular}

Rank position, 1 = lowest GHQ score; 22 = highest GHQ score. artefact of place composition and there is not a geography of mental health, in terms of single overall ward or regional differences affecting all types of people, which remains after compositional control and results from higher level contextual effects.

Area variations in mental health could, however, be more complex. This is the situation proposed by Lewis and Booth when they suggested that there was no regional variability in GHQ scores for people in social classes I and II and that it was reduced for those living in urban areas with no access to open spaces. Thus, they suggested that there are different place effects for different types of people. Their conclusions in this respect should be treated with caution, however, as their models assess this variation without controlling for the compositional effects of any other individual level characteristics. This problem can be avoided by using a third type of multilevel model, the complex variation model. In these models, it is possible to allow the parameter estimates relating to any particular explanatory variable to vary from area to area while at the same time controlling for compositional effects.

\section{Results}

The crude average GHQ scores as recorded in the health and lifestyle survey according to The Economist regionalisation scheme are shown in table 2 . The regional averages range from a high of 5.25 in Merseyside to a low of 3.15 in rural Wales. As these are simple aggregate rates, the variation displayed in table 2 may be an artefact of either population composition or of sampling fluctuations.

Table 3 Multi-level estimates

\begin{tabular}{|c|c|c|}
\hline & $\stackrel{\text { (A) }}{\text { Null model }}$ & $\begin{array}{l}\text { (B) } \\
\text { Random-intercepts } \\
\text { model }\end{array}$ \\
\hline \multicolumn{3}{|l|}{$\begin{array}{l}\text { Fixed effects } \\
\text { Level } 1 \text { (individual) }\end{array}$} \\
\hline Intercept & 4.05 & 3.63 \\
\hline Age & & $-0.01(-2.75)$ \\
\hline Sex - male & & $-0.90(-7.09)$ \\
\hline I\&II & & $-0.31(-1.93)$ \\
\hline IV $\&$ V & & $0.11(0.61)$ \\
\hline III non-manual & & $-0.16(-0.79)$ \\
\hline Other & & $0.40(0.82)$ \\
\hline \multicolumn{3}{|l|}{ Marital status: } \\
\hline Single & & $-0.04(-0.19)$ \\
\hline Widowed & & $0.96(3.67)$ \\
\hline Divorced/separated & & $1.50(5.53)$ \\
\hline Employment status - & & $1.59(5.24)$ \\
\hline $\begin{array}{l}\text { Illness - limiting long } \\
\text { term }\end{array}$ & & $2 \cdot 92(17 \cdot 15)$ \\
\hline Living environment: & & \\
\hline $\begin{array}{l}\text { Urban without space } \\
\text { Country } \\
\text { Other }\end{array}$ & & $\begin{array}{l}0.25(1.67) \\
-0.48(-2.80) \\
-0.23(-0.42)\end{array}$ \\
\hline \multicolumn{3}{|l|}{ Housing status: } \\
\hline $\begin{array}{l}\text { Local authority renter } \\
\text { Other renter }\end{array}$ & & $\begin{array}{l}0.51(3.24) \\
0.32(1.33)\end{array}$ \\
\hline $\begin{array}{l}\text { Ethnicity: } \\
\text { Non-white } \\
\text { Unknown }\end{array}$ & & $\begin{array}{l}1.21(2.92) \\
0.81(0.93)\end{array}$ \\
\hline \multicolumn{3}{|l|}{$\begin{array}{l}\text { Random effects variance } \\
\text { Level } 3 \text { (region) }\end{array}$} \\
\hline $\begin{array}{l}\text { Intercept } \\
\text { Level } 2 \text { (ward) }\end{array}$ & $0.12(1 \cdot 70)$ & $0.04(1.03)$ \\
\hline $\begin{array}{l}\text { Level } 2 \text { (ward) } \\
\text { Intercept }\end{array}$ & $0.27(1.97)$ & $0.07(0.60)$ \\
\hline Level 1 (individual) & & \\
\hline Intercept & $26 \cdot 82$ & 25 \\
\hline
\end{tabular}

Note: estimates represent GHQ score points; figures in parentheses represent ratio of estimates to standard error. 
Table 4 Multi-level estimates of complex variation models

\begin{tabular}{|c|c|c|}
\hline & Model (A) & Model (B) \\
\hline $\begin{array}{l}\text { Fixed effects } \\
\text { Level } 1 \text { (individual): } \\
\text { Intercept } \\
\text { Age } \\
\text { Sex - male }\end{array}$ & $\begin{aligned} & 3.63 \\
-0.01(-2.83) & (-0.91(-7 \cdot 10)\end{aligned}$ & $\begin{aligned} & 3.63 \\
-0.01(-2.71) & (-9.90(-7 \cdot 10)\end{aligned}$ \\
\hline $\begin{array}{l}\text { Social class: } \\
\text { I\&II } \\
\text { IV\&V } \\
\text { III non-manual } \\
\text { Other }\end{array}$ & $\begin{array}{l}-0.30(-1.88) \\
0.04(0.21) \\
-0.16(-0.77) \\
0.40(0.82)\end{array}$ & $\begin{aligned}-0.30(-1.89) \\
0.10(0.59) \\
-0.16(-0.79) \\
0.40(0.82)\end{aligned}$ \\
\hline $\begin{array}{l}\text { Marital status: } \\
\text { Single } \\
\text { Widowed } \\
\text { Divorced/separated }\end{array}$ & $\begin{array}{c}-0.03(-0.17) \\
0.96(3.67) \\
1.52(5.59)\end{array}$ & $\begin{array}{c}-0.04(-0.22) \\
0.93(3.58) \\
1.51(5.55)\end{array}$ \\
\hline $\begin{array}{l}\text { Employment status - } \\
\text { unemployed }\end{array}$ & $1.60(5 \cdot 26)$ & $1 \cdot 60(5 \cdot 26)$ \\
\hline $\begin{array}{l}\text { Illness - limiting long } \\
\text { term } \\
\text { Living environment: }\end{array}$ & $2.93(17 \cdot 17)$ & $2 \cdot 92(17 \cdot 13)$ \\
\hline $\begin{array}{l}\text { Urban without space } \\
\text { Country } \\
\text { Other }\end{array}$ & $\begin{array}{l}0.24(1.64) \\
-0.48(-2.80) \\
-0.23(-0.42)\end{array}$ & $\begin{aligned} & 0.24(1.54) \\
-0.49(-2.78) & (-0.19(-0.34)\end{aligned}$ \\
\hline $\begin{array}{l}\text { Housing status: } \\
\text { Local authority } \\
\text { renter } \\
\text { Other renter }\end{array}$ & $\begin{array}{l}0.53(3.33) \\
0.32(1.32)\end{array}$ & $\begin{array}{l}0.53(3.32) \\
0.34(1.40)\end{array}$ \\
\hline $\begin{array}{l}\text { Ethnicity: } \\
\text { Non-white } \\
\text { Unknown }\end{array}$ & $\begin{array}{l}1.20(2.91) \\
0.78(0.90)\end{array}$ & $\begin{array}{l}1.19(2.88) \\
0.81(0.93)\end{array}$ \\
\hline $\begin{array}{l}\text { Random effects variance } \\
\text { Level } 3 \text { (region): } \\
\text { Intercept } \\
\text { IV\&V }\end{array}$ & $\begin{array}{l}0.04(0.83) \\
0.29(1.20)\end{array}$ & $0.05(1 \cdot 12)$ \\
\hline $\begin{array}{l}\text { Level } 2 \text { (ward): } \\
\text { Intercept } \\
\text { Urban without space }\end{array}$ & $0.06(0.50)$ & $\begin{array}{l}0.21(1.27) \\
1.17(1.97)\end{array}$ \\
\hline $\begin{array}{l}\text { Level } 1 \text { (individual): } \\
\text { Intercept } \\
\text { Random effects covariance } \\
\text { Level } 3 \text { (region): }\end{array}$ & $24 \cdot 96$ & $24 \cdot 81$ \\
\hline $\begin{array}{l}\text { Intercept/IV\&V } \\
\text { Level } 2 \text { (ward): } \\
\text { Intercept/Urban } \\
\text { without space }\end{array}$ & $-0.01(-0.19)$ & $-0.51(-1.78)$ \\
\hline
\end{tabular}

Estimates represent GHQ score points; figures in parenthese represent ratio of estimates to standard error. As these models contain more than one random term, random effects covariance terms are also estimated.

To examine this possibility a simple three level "null" model was fitted and the results are summarised in table 3 , column $A$. The intercept gives the nationwide average GHQ score and is estimated at $4 \cdot 05$. This value does not remain constant across either regions or wards and the random effects variance at the bottom of table 3 (column A) show the level to which the remaining variability can be apportioned. These values show that most variation $(98.6 \%)$ occurs at level 1 (between individuals), and very small amounts occur at the higher levels $-1.01 \%$ at the ward level and $0.44 \%$ at the regional level (these values are obtained by dividing the variation at each level by the total variation at all three levels). These higher level terms can be tested for significance by calculating the ratio of estimates to their standard error. If the ratio is more than \pm 2 , the estimate is judged to be significantly different from zero at the 0.05 level. As shown in table 3 (column A) neither of the higher level random terms meets this criteria, although the ward level variation approaches significance. Model A includes no individual level explanatory variables. Consequently, it does not provide evidence that the crude averages in table 2 are an artefact of varying regional compositions; instead it suggests that the variations result from sampling fluctuations.
The extent of any compositional artefact effect can be assessed by including individual level explanatory variables (table 3, column B). The intercept term now represents the stereotypical respondent to the GHQ in the health and lifestyle survey. The estimates show that GHQ scores are significantly higher if the respondent is widowed, divorced, or separated; unemployed; incapacitated by long term illness; renting local authority housing; or from an ethnic minority. In contrast, GHQ scores are significantly lower if the respondent is older, male, or living in the country. Interestingly, there are no large differences in score on the basis of social class, although there is some suggestion that social groups I and II have slightly lower scores.

The inclusion of the compositional explanatory terms reduces the variance of the random intercepts at both of the two higher levels and this is especially noticeable at the ward level. The variance that remains at these levels quantitatively measures contextual effects on GHQ scores assuming single overal area differentials and controlling for individual compositional factors. As can be seen, neither ward nor regional contextual effects are near significance and the variance that can be attributed to these two levels has been reduced to $0 \cdot 26 \%$ and $0.15 \%$ respectively. The regional geography of GHQ scores before and after controlling for individual compositional factors is shown in the figure, which plots the regional differences compared to the national average obtained from each of these two initial models.

While there is no evidence of single overall area differences, it may be that the scores of particular types of individuals vary across regions and wards. The suggestions of Lewis and Booth relating to social class and external living environment to this end were examined. In terms of social class non-zero, but non-statistically significant, variation was found at the regional level for the base category (III manual) and social groups IV and V (table 4, column A). As can be seen none of the new random terms reach significance when the estimates are compared to their standard errors. It should be noted, however, that this form of significance testing is less reliable for random parameters than fixed parameters. A more reliable testing procedure is to calculate a likelihood ratio statistic before and after the extra random terms have been included as the difference of the likelihoods follows a $\chi^{2}$ distribution with degrees of freedom equal to the number of new parameters. This test confirmed the non-significance of the new terms (difference in likelihood ratio $=3 \cdot 3, \mathrm{df}=2, \mathrm{p}=0 \cdot 19)$. It seems, therefore, that there is no significant regional variation in GHQ scores for any of the social class categories used here. At the ward level the only variation detected was a very small and non-significant amount for social groups IV and V (results not presented).

In terms of the immediate living environment, no significant differing variability was found at the regional level for any of the categories (results not presented). However, there was some suggestion of differing vari- 


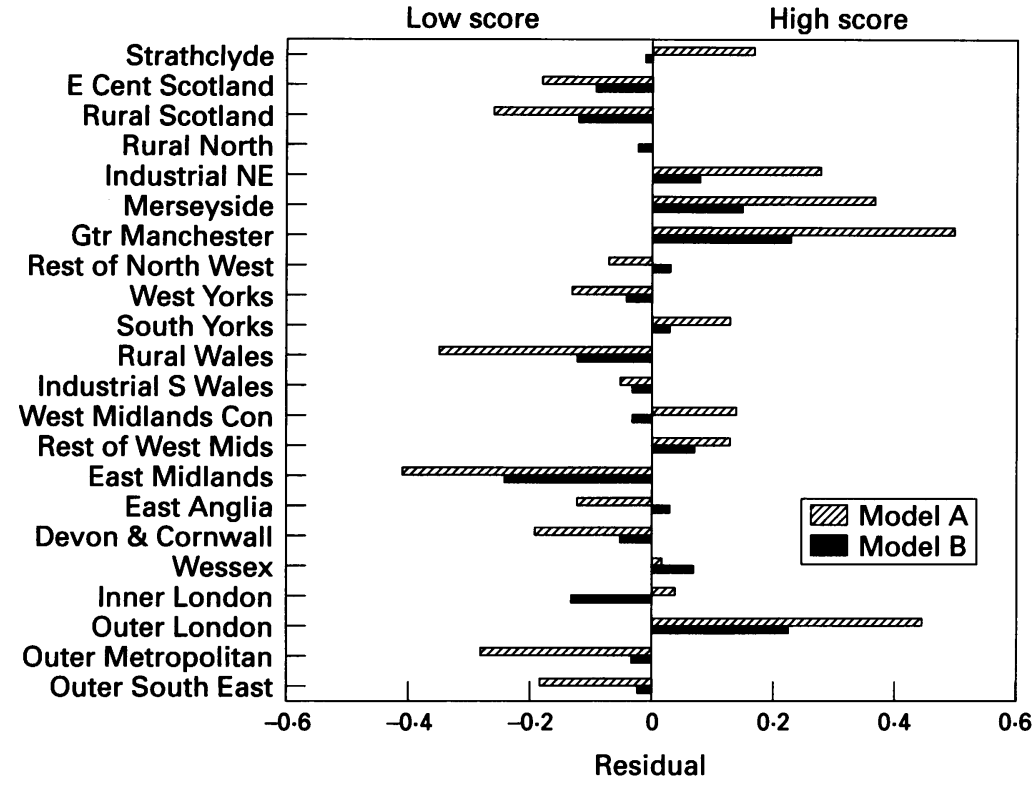

Regional differences in the general health questionnaire scores.

ability at ward level for those living in urban areas without an adjacent open space (table 4, column B) (difference in likelihood $=5 \cdot 10, \mathrm{df}=$ $2, p=0.08$ ); it seems that being in a particular ward may have some differential effect for people with this type of immediate, external living environment.

\section{Discussion}

This study has shown only small variations in the prevalence of psychiatric morbidity at both electoral ward and regional levels. These are the result of sampling fluctuations and varying regional population compositions rather than higher level contextual effects. Certainly, there is no evidence for a clear north-south distinction in psychiatric wellbeing, as was suggested by Blaxter and Lewis and Booth, and the study also finds no evidence for Lewis and Booth's suggestion that there are regional differences in the effects of individual social class and living environment. Although this study uses a different response variable, Lewis and Booth themselves recognise there is no reason why this in itself would produce different results. It is likely that these new results arise from using a technically more robust statistical method together with a more sophisticated regionalisation.

The local neighbourhood does not seem to have any special importance beyond the type of people that reside there, and this study does not therefore support Blaxter's conclusion about the relative importance of area effects at different spatial scales. The study does, however, produce some support, in terms of a regional effect, for the hypothesis that urban living impairs mental health. ${ }^{12}$ The most highly urbanised regions of Strathclyde, the industrial north east, Merseyside and Greater Manchester have higher GHQ scores, while more rural regions (rural Scotland, rural Wales, and Devon and Cornwall) have low scores. Inner London is an interesting exception; the figure shows that its residual goes from positive to negative when the explanatory variables are included showing that this urban area actually has a lower GHQ score than its population composition would suggest.

The most striking impression from the figure, however, is that all the regional effects are minimal both before and after controlling for composition. Before controlling for composition, the effects are all within the range of \pm 0.5 points of the national average GHQ score; afterwards they are all within \pm 0.25 points of the national average GHQ score. It seems, therefore, that in terms of low level psychiatric disturbance it is the characteristics of individuals and not the characteristics of areas that are important. This study has shown that mental wellbeing is associated with an individual's position in terms of gender, marital status, employment status, physical health, immediate living environment, and ethnicity. It should also be noted, however, that a large degree of individual variation remains "unexplained", as the variation between individuals is reduced by a small amount only when the explanatory variables are included (see table 3 , columns A \& B). Interestingly, the analysis also showed no large social class differences, and therefore supports the recent call for the health inequalities debate to be broadened by considering a range of social locations and not just those deriving from economic activity. ${ }^{30}$ In terms of psychiatric disturbance, measures of social isolation may be especially important and their omission in this analysis may account for the "unexplained" individual variation.

While this study has suggested the primacy of individual characteristics in underpinning psychiatric morbidity, it should not be concluded that geographical locales have no importance for mental health. As a recent paper suggests, ${ }^{4}$ studies which attempt to classify area variations into compositional and contextual effects carry an implicit assumption that the type of area a person lives in is independent of a person's social class position. This assumption is unrealistic, and while the characteristics of areas may not have a direct independent role they may still operate as important mediating factors between social class and health. Consequently, the findings presented here should not be interpreted as suggesting that public health interventions targeted at mental health issues should exclude strategies that focus on improving the social and physical environment. Furthermore, although this study is based on self reported assessments, and individual level associations should not be distorted by differences in diagnostic procedures, they will be susceptible to variations in the willingness to report emotional difficulties and this is likely to be particularly important in relation to the gender difference identified here. ${ }^{31}$

Psychiatric morbidity represents a major challenge for public health and does, undoubtedly, warrant as much attention as physical illness. As the information base is expanding, and robust statistical multilevel methods are now available, further work needs 
to be conducted on area variations in mental health, especially at the regional level and particularly with regard to more serious psychiatric conditions.

We thank the ESRC Data Archive at the University of Essex for providing the health and lifestyle survey data. ${ }^{32}$

1 Crombie LK, Kenicer MB, Smith WCS, Tunstall-Pedoe HD. Unemployment, socio-environmental factors and coronary heart disease. Br Heart f 1989;61:172-7.

2 Carstairs V, Morris R. Deprivation: explaining differences in mortality between Scotland and England and Wales. BMF 1989;299:886-9.

3 Townsend P, Phillimore P, Beattie A. Health and deprivation inequality and the north. London: Croom Helm, 1988.

4 Macintyre S, MacIver S, Sooman A. Area, class and health: should we be focusing on places or people? foumal of Should we be focusing on plac
Social Policy 1993;22:213-34.

5 Macintyre $S$. The patterning of health by social position in contemporary Britain: directions for sociological research. Soc Sci Med 1986;23:393-415.

6 Schwartz S. The fallacy of the ecological fallacy: the potential misuse of a concept and the consequences. Am $\mathcal{F}$ Public Health 1994;84:819-23.

7 Blaxter M. Health and lifestyles. London: Tavistock/Routledge, 1990.

8 Haan M, Kaplan GA, Camacho T. Poverty and health: prospective evidence from the Alameda County Study. Am f Epidemiol 1987;125:989-98.

9 Phillimore P. How do places shape health? Rethinking locality and lifestyle in north-east England. In: Platt S, Thomas H, Scott S, Williams G, eds. Locating health: sociological and historical explorations. Aldershot: Avebury, 1993:163-77.

10 Giggs JA. The spatial ecology of mental illness. In: Smith CJ, Giggs JA, eds. Location and stigma: contemporary perSJ, Giggs JA, eds. Location and stigma: contemporary perspectives on mental health and men

11 Shepherd $M$. Urban factors in mental disorders - an epidemiological approach. $\mathrm{Br}$ Med Bull 1984;40:401-4.

12 Blazer DG, George LK, Landerman R, et al. Psychiatric disorders: a rural/urban comparison. Arch Gen Psychiatry 1985;42:651-6.

13 Department of Health. On the state of the public health: the annual report of the chief medical officer of the Department of Health for the year 1992. London: HMSO, 1993.
14 Cox BD, Blaxter M, Buckle ALJ, et al. The health and lifestyle survey. Cambridge: Health Promotion Research Trust, 1987.

15 Lewis G, Booth M. Regional differences in mental health in Great Britain. $f$ Epidemiol Community Health 1992;46: $608-11$

16 Goldberg $D$. The detection of psychiatric illness by questionnaire. London: Oxford University Press, 1972. Maudsley Monograph no 21 .

17 Research Unit on Health and Behavioural Change. Changing the public health. Chichester: John Wiley, 1989.

18 Goldstein H. Multilevel models in social and educational re search. London: Griffin, 1987.

19 Duncan C, Jones K, Moon G. Do places matter? A multileve analysis of regional variations in health-related behaviour in Britain. Soc Sci Med 1993;37:725-33.

20 Humphreys K, Carr-Hill R. Area variations in health outcomes: artefact or ecology. Int f Epidemiol 1991;20:251-8.

21 Jones K, Duncan C. Individuals and their ecologies: analysing the geography of chronic illness within a multilevel modelling framework. Fournal of Place and Health 1994 (in press).

22 Aitken MA, Longford NT. Statistical modelling issues in school effectiveness studies. $\mathcal{F}$ Stat Soc $A$ 1986;149: $1-26$

23 Scott AJ, Holt D. The effects of two-stage sampling on OLS methods. Fournal of the American Statistical Association 1982;77:848-54.

24 Skinner $\mathrm{C}$, Holt $\mathrm{D}$, Smith TF, eds. The analysis of complex surveys. New York: Wiley, 1989.

25 Jones K. Using multilevel models for survey analysis. fournal of the Market Research Society 1993;35:249-65.

26 Jones $\mathrm{K}$, Moon G. Re-assessing immunisation uptake as a performance measure in general practice. $B M \mathcal{F} 1991 ; 303$ : 28-31

27 Jones K, Moon G, Clegg A. Ecological and individual effects in childhood immunisation uptake: a multilevel approach. Soc Sci Med 1991;33:501-8.

28 Tarnopolsky $A$, et al. Validity and use of a screening questionnaire (GHO) in the community. Br $\mathcal{F}$ Psychiatry 1979 , 134:508-15.

29 Prosser R, Rasbash J, Goldstein H. ML3: software for threelevel analysis. London: Institute of Education, University of London, 1991

30 Platt S, Thomas H, Scott S, Williams G, eds. Locating health: sociological and historical explorations. Aldershot: Avebury, 1993

31 Briscoe M. Sex differences in psychological well-being. Psychol Med 1982, Monograph Suppl 1.

32 Cox BD. Health and lifestyle survey, 1984-5. Computer file. Colchester: ESRC Data Archive. 